\title{
Distribution of the Na,K-ATPase $\alpha$ Subunit in the Rat Spiral Ganglion and Organ of Corti
}

\author{
Will J. Mclean ${ }^{1}$, K. Anne Smith ${ }^{1}$, Elisabeth Glowatzki ${ }^{2}$, and Sonja J. Pyott ${ }^{1}$ \\ ${ }^{1}$ Department of Biology and Marine Biology, University of North Carolina Wilmington, 601 South College Road, \\ Wilmington, NC 28403, USA \\ ${ }^{2}$ Department of Otolaryngology Head and Neck Surgery, Johns Hopkins School of Medicine, 720 Rutland Ave, Ross 824, \\ Baltimore, MD 21205, USA
}

Received: 10 September 2008; Accepted: 20 November 2008; Online publication: 12 December 2008

\begin{abstract}
Processing of sound in the cochlea involves both afferent and efferent innervation. The Na,K-ATPase (NKA) is essential for cells that maintain hyperpolarized membrane potentials and sodium and potassium concentration gradients. Heterogeneity of NKA subunit expression is one mechanism that tailors physiology to particular cellular demands. Therefore, to provide insight into molecular differences that distinguish the various innervation pathways in the cochlea, we performed a variety of double labeling experiments with antibodies against three of the $\alpha$ isoforms of the NKA (NKA $\alpha 1-3)$ and markers identifying particular subsets of neurons or supporting cells in whole mount preparations of the organ of Corti and spiral ganglion. We found that the NKA $\alpha 3$ is abundantly expressed within the membranes of the spiral ganglion somata, the type I afferent terminals contacting the inner hair cells, and the medial efferent terminals contacting the outer hair cells. We also found expression of the NKA $\alpha 1$ in the supporting cells that neighbor the inner hair cells and express the glutamate transporter GLAST. These findings suggest that both the NKA $\alpha 1$ and NKA $\alpha 3$ are poised to play an essential role in the regulation of the type I afferent synapses, the medial efferent synapses, and also glutamate transport from the afferent-inner hair cell synapse.
\end{abstract}

Keywords: hair cell, afferent, efferent, hearing, auditory nerve

Correspondence to: Sonja J. Pyott $\cdot$ Department of Biology and Marine Biology . University of North Carolina Wilmington . 601 South College Road, Wilmington, NC 28403, USA. Telephone: +1-9109622500; fax +1-910-9624066; email: pyotts@uncw.edu

\section{INTRODUCTION}

Processing of sound in the cochlea involves both afferent and efferent innervation. The majority of afferent fibers, the myelinated type I fibers, make glutamatergic synapses with the inner hair cells (IHCs) and allow fast and precise transmission to the brain (Fuchs et al. 2003). Unmyelinated type II fibers make en passant synapses onto the outer hair cells (OHCs; Spoendlin 1973) and have a yet unknown role. Efferent feedback to the cochlea is provided by olivocochlear fibers originating in the brainstem. Activation of myelinated medial efferent terminals contacting OHCs suppresses cochlear function (Guinan 1996). Activation of the unmyelinated lateral efferent fibers that form axodendritic synapses onto type I afferent fibers causes either slow suppression or enhancement of afferent activity (Groff and Liberman 2003).

Mechanisms to maintain hyperpolarized membrane potentials and restore intracellular concentration gradients are essential for excitable cells and vary depending on their particular physiology (Blanco 2005). The Na,KATPase (NKA) is a membrane-bound protein that uses energy from the hydrolysis of adenosine triphosphate (ATP) to extrude three sodium ions for every two potassium ions taken into the cell. Neurons with high firing rates especially depend upon the NKA to sustain activity, since the NKA maintains concentration gradients and also hyperpolarizes the membrane. The functional NKA is comprised of two $\alpha$ subunits, which contain the residues necessary for ATP hydrolysis and ion transport and two $\beta$ subunits. The diversity of $\alpha(1-4), \beta$ (1-3), and 
also FXYD (1-7) subunits (Geering 2005) and the highly regulated tissue-specific and developmental expression patterns are no doubt responsible for tailoring the NKA transport properties to specific cellular demands. In this study, we investigated the neuronal distribution of the NKA $\alpha$ subunit (NKA $\alpha)$ in the cochlea to determine its contribution to setting and modulating activity patterns in the various neuronal cell types.

Because inhibitors of the NKA $\alpha$ are known to reduce the endocochlear potential (Konishi and Mendelsohn 1970), previous research investigating the localization of the NKA $\alpha$ in the cochlea has focused on its expression in structures, like the stria vascularis and spiral ligament, responsible for maintaining the endocochlear potential (Wangemann 2006). Nonetheless, earlier work also reported expression of the NKA $\alpha$ in the neuronal elements of the mammalian cochlea using a variety of techniques, including enzyme cytochemistry (Kerr et al. 1982), in situ hybridization (Ryan and Watts 1991), and immunohistochemistry (Schulte and Adams 1989; Iwano et al. 1990; McGuirt and Schulte 1994; Schulte and Steel 1994; ten Cate et al. 1994; Nakazawa et al. 1995; Zuo et al. 1995; Erichsen et al. 1996; Peters et al. 2001; Weber et al. 2001).

Using immunofluorescence in whole-mount preparations of the organ of Corti and spiral ganglion, we performed a variety of double labeling experiments with antibodies against the NKA $\alpha$ and markers identifying particular subsets of neurons or supporting cells within the cochlea. Our results unambiguously identify the cell types expressing particular isoforms of the NKA $\alpha$ and, importantly, suggest novel roles for the NKA $\alpha$ in regulating neuronal activity in the cochlea.

\section{METHODS}

\section{Immunostaining}

Immunostaining of organs of Corti was performed as described previously (Pyott et al. 2004, 2007). All animal protocols were approved by the University of North Carolina at Wilmington Animal Care and Use Committee. Whole cochleae were dissected from rats and immediately perfused through the round window with $4 \%$ paraformaldehyde (PFA) in phosphate-buffered saline (PBS) at $\mathrm{pH}$ 7.4. Cochleae were fixed in $4 \%$ PFA/PBS for 1 to $3 \mathrm{~h}$ at $4^{\circ} \mathrm{C}$ before being rinsed with PBS. Apical turns of the organs of Corti were then dissected from the cochleae and treated with a blocking buffer (PBS with 5\% normal goat or donkey serum and 0.2\% Triton X-100) for 1 to $3 \mathrm{~h}$ at room temperature. Turns were incubated in the primary antibody diluted in blocking buffer overnight at $4^{\circ} \mathrm{C}$ and then rinsed three times for 20 min in PBS with $0.2 \%$ Triton X-100 (PBT).
After rinsing, the turns were then incubated in the secondary antibody diluted in blocking buffer for $2 \mathrm{~h}$ at room temperature, rinsed three times for $20 \mathrm{~min}$ in PBT, and rinsed in PBS before mounting on glass slides in Vectashield mounting medium (Vector Labs). All incubations and rinses were performed on a rocking table. Rats were between 20 and 24 days old. Table 1 summarizes the primary antibodies used. Secondary antibodies (Alexa Fluor 488 and 594 generated in either goat or donkey) were purchased from Molecular Probes and diluted 1:1,000 in blocking buffer. For all antibodies, experiments performed in the absence of primary antibody showed no immunoreactivity. All data were collected from at least three independently replicated experiments.

\section{Specificity of NKA $\alpha$ antibodies}

The NKA $\alpha$ antibodies used in this study were chosen because their specificity has been well characterized previously. Specificity of the antibodies for the NKA $\alpha 3$ has been verified by the vendor using Western blot analysis of rat brain extracts (sc-16052) or canine skeletal muscle extracts (MA3-915). Specificity of the antibodies for the NKA $\alpha 1$ has been verified by the vendor using Western blot analysis of rat brain microsomes (C464.6) and by Arystarkhova and Sweadner (1996) using Western blot analysis of membrane preparations from rat kidney, brainstem, and adult and neonatal heart $(\alpha 6 \mathrm{~F})$. Specificity of the antibodies for the NKA $\alpha 2$ has been verified by Pressley (1992) using Western blot analysis of rat brain microsomes (anti-HERED) and by the vendor using immunohistochemistry to show membrane localization in rat retinal cells.

\section{Microscopy}

Fluorescence images were acquired using an Olympus Fluoview FV1000 confocal microscope with a 60× Olympus PlanoApo oil immersion lens (N. A. 1.42) under the control of the Olympus Fluoview FV1000 version 1.6a software. z-Stacks (30 to 90 optical sections) and were collected at 0.3 to $0.5 \mu \mathrm{m}$. Except for subpanels D-I in Figure 7, which are micrographs of single optical sections, all images are presented as z-projections through the entire optical stack.

\section{RESULTS}

\section{The NKA 3 is expressed in the spiral ganglion} and the organ of Corti

To investigate the neuronal distribution of the NKA $\alpha$ in the spiral ganglion and organ of Corti, we immunolabeled apical cochlear turns from rats aged 
TABLE 1

\begin{tabular}{|c|c|c|c|c|}
\hline \multicolumn{5}{|c|}{ Primary antibodies used in the study } \\
\hline Antibody & Antigen & Host & Supplier & Dilution \\
\hline AB5054 & Rat calretinin & Rabbit polyclonal & Chemicon & $1: 1,000$ \\
\hline sc-22692 & Human Prestin & Goat polyclonal & Santa Cruz Biotechnology & $1: 400$ \\
\hline sc-16052 & Human NKA $\alpha 3$ & Goat polyclonal & Santa Cruz Biotechnology & $1: 300$ \\
\hline MA3-915 & Canine NKA $\alpha 3$ & Mouse monoclonal & Affinity Bioreagents & $1: 500$ \\
\hline AB1989 & $\begin{array}{l}\text { Peptide derived from rat } \\
\text { neurofilament } 200 \text { sequence }\end{array}$ & Rabbit polyclonal & Chemicon & $1: 500$ \\
\hline AB1530 & Rat Peripherin & Rabbit polyclonal & Chemicon & $1: 300$ \\
\hline AB1543P & Bovine Synapsin & Rabbit polyclonal & Chemicon & $1: 500$ \\
\hline K58/35 & $\begin{array}{l}\text { Peptide derived from } \\
\text { conserved sequence of the } \\
\text { sodium channel }\end{array}$ & Mouse monoclonal & $\begin{array}{l}\text { Generously provided by Dr. James } \\
\text { Trimmer, University of California } \\
\text { Davis }\end{array}$ & $1: 100$ \\
\hline sc-16049 & Human NKA $\alpha 2$ & Goat polyclonal & Santa Cruz Biotechnology & $1: 200$ \\
\hline Anti-HERED & $\begin{array}{l}\text { Peptide derived from rat } \\
\text { NKA } \alpha 2 \text { sequence }\end{array}$ & Rabbit polyclonal & $\begin{array}{l}\text { Generously provided by Dr. Thomas } \\
\text { Pressley, Texas Tech University }\end{array}$ & $1: 200$ \\
\hline C464.6 & Rabbit NKA $\alpha 1$ & Mouse monoclonal & Upstate & $1: 600$ \\
\hline$\alpha 6 \mathrm{~F}$ & Chicken NKA $\alpha 1$ & Mouse Monoclonal & $\begin{array}{l}\text { Developmental Studies Hybridoma } \\
\text { Bank }\end{array}$ & $1: 300$ \\
\hline
\end{tabular}

P20 to P25 with antibodies against NKA $\alpha 3$, the neuronal NKA $\alpha$ isoform (red; Fig. 1A). To better localize NKA $\alpha 3$ immunoreactivity, we double-labeled apical cochlear turns with a polyclonal anti-calretinin antibody (green; Fig. 1B). Calretinin is an endogenous calcium buffer enriched in sensory hair cells as well as type I afferent neurons (Dechesne et al. 1991; Dechesne et al. 1993; Zheng and Gao 1997). Lowmagnification micrographs of apical cochlear turns show that NKA $\alpha 3$ immunoreactivity is localized to the spiral ganglion somata and fibers in the IHC and OHC region of the organ of Corti (Fig. 1B). Similar patterns of NKA $\alpha 3$ immunoreactivity were seen in middle and basal cochlear turns (data not shown).

To confirm the specificity of the monoclonal antibody against NKA $\alpha 3$, double labeling experiments with a monoclonal and polyclonal anti-NKA $\alpha 3$ were performed (Fig. 1C-K). High magnification micrographs show colocalized immunoreactivity for both the monoclonal (red) and polyclonal (green) anti-NKA $\alpha 3$ for the spiral ganglion somata (Fig. 1C-E) and fibers within the inner (Fig. 1F-H) and outer (Fig. 1I-K) hair cell region. Additionally, both antibodies show immunoreactivity restricted to the cell membranes, consistent with the transmembrane localization of the NKA $\alpha$. The patterns of immunoreactivity for both the monoclonal and polyclonal anti-NKA $\alpha 3$ suggest that both antibodies are specifically recognizing the NKA $\alpha 3$ in the rat organ of Corti and spiral ganglion. To unambiguously identify the structures expressing NKA $\alpha 3$, we undertook a series of double labeling experiments with antibodies against NKA $\alpha 3$ and known markers of the specific neuronal cell types in the cochlea.
NKA 3 is present in type I but not in type II spiral ganglion somata

Neurofilament 200 (NF200) is an intermediate filament enriched in the cytoplasm of both types I and II spiral ganglion somata and processes (Berglund and Ryugo 1991). Double labeling experiments with a monoclonal anti-NKA $\alpha 3$ (red; Fig. 2A) and a polyclonal anti-NF200 (green; Fig. 2B) revealed that the majority of NF200-positive spiral ganglion somata also show surface expression of NKA $\alpha 3$ (Fig. 2C). However, in all experiments, a small subset of spiral ganglion somata did not show NKA $\alpha 3$ immunoreactivity (marked with an asterisk in Fig. 2C). To determine if this subset of somata belong to type II spiral ganglion neurons (SGNs), we double-labeled organs of Corti with a monoclonal anti-NKA $\alpha 3$ (red; Fig. 2D) and a polyclonal anti-peripherin (green; Fig. 2E). Peripherin is an intermediate filament enriched in the cytoplasm of type II SGNs (Hafidi 1998). These experiments show that the peripherin-positive type II SGNs do not show surface expression of NKA $\alpha 3$ (Fig. 2F) and suggest that NKA $\alpha 3$ is restricted to the type I spiral ganglion somata.

\section{$N K A \alpha 3$ is present in type I afferent terminals contacting the IHCs}

As seen in Figure 1B, higher magnification micrographs of organs of Corti double-labeled with antiNKA $\alpha 3$ (red; Fig. 3A) and anti-calretinin (green; Fig. 3B) show that the calretinin-positive afferent fibers contacting the calretinin-positive IHCs express NKA $\alpha 3$ (Fig. 3C). To further confirm localization of 
NKA $\alpha 3$

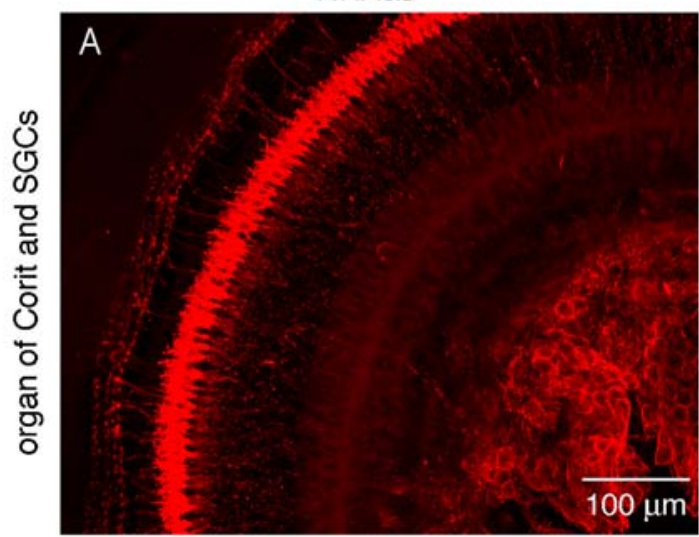

\section{NKA $\alpha 3 /$ Calretinin}

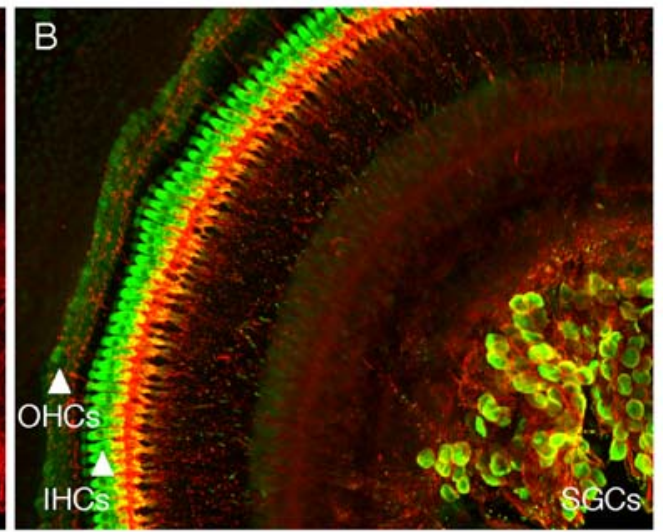

Polyclonal NKA $\alpha 3$
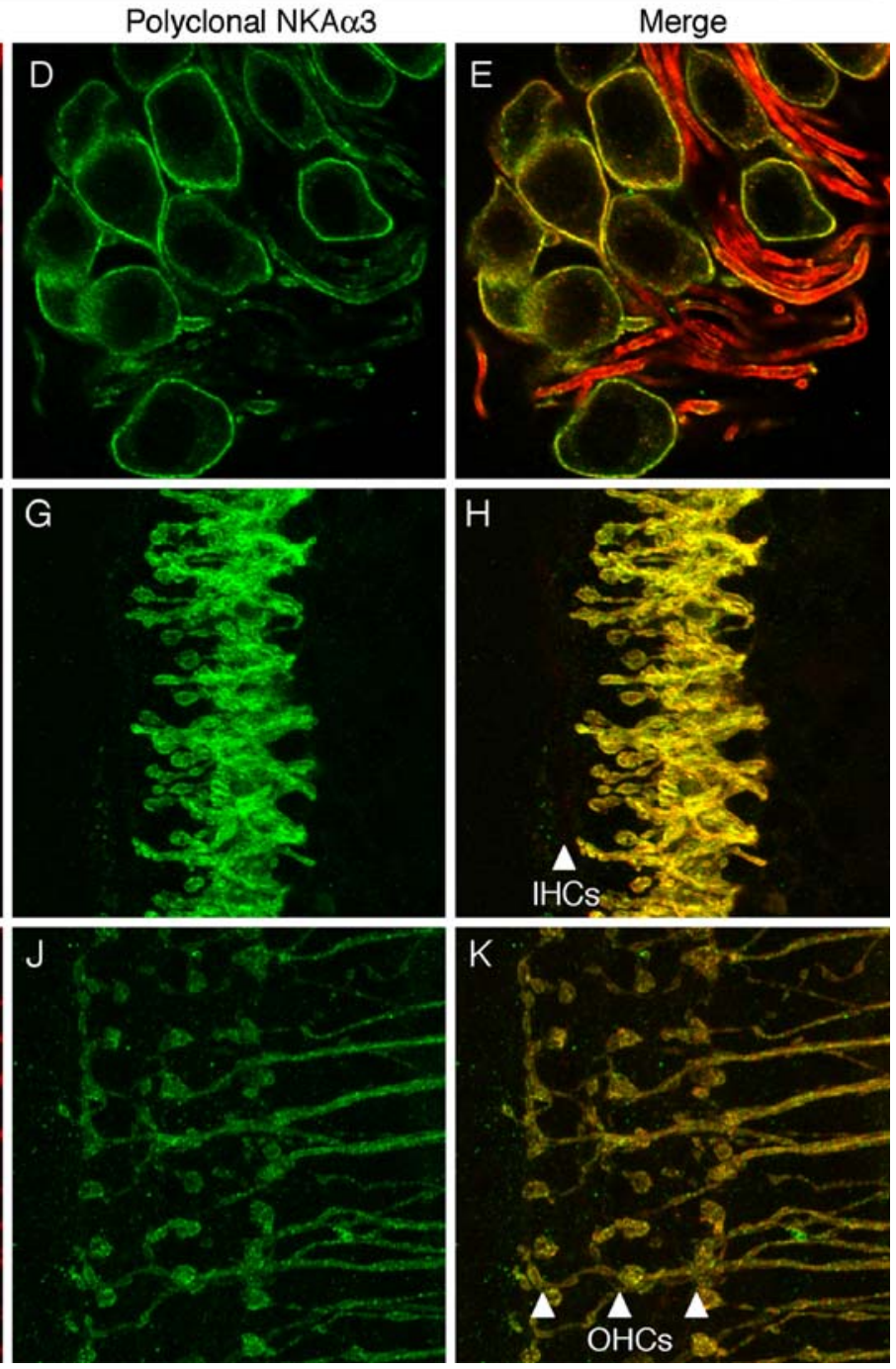

FIG. 1. NKA $\alpha 3$ is present in the spiral ganglion somata and organ of Corti. Low-magnification micrographs of apical cochlear turns immunolabeled with a monoclonal anti-NKA $\alpha 3$ (red) show abundant NKA 33 immunoreactivity in the organ of Corti and spiral ganglion (A). Double labeling with a monoclonal anti-NKA 33 (red) and a polyclonal anticalretinin (green) shows that NKA 33 immunoreactivity is localized to the spiral ganglion somata and fibers contacting the inner and outer hair cells (B). High-magnification micrographs of apical cochlear turns doublelabeled with a monoclonal anti-NKA $\alpha 3$ (red) and a polyclonal antiNKA 3 (green) reveal similar patterns of immunoreactivity in the membranes of the spiral ganglion somata $(\mathbf{C}-\mathbf{E})$, fibers terminating onto the inner hair cells $(\mathbf{F}-\mathbf{H})$, and fibers terminating onto the outer hair cells (I-K). Localization of NKA 33 immunoreactivity to membranes and colocalized immunoreactivity with different antibodies against the NKA 33 suggest that both antibodies are specifically labeling the NKA $\alpha 3$. Importantly, NKA $\alpha 3$ immunoreactivity appears restricted to the spiral ganglion somata and neuronal elements of the organ of Corti. For orientation, the location of the single row of inner hair cells (IHCs), three rows of outer hair cells (OHCs), and region containing the spiral ganglion cells (SGCs) have been indicated (with a triangle). 


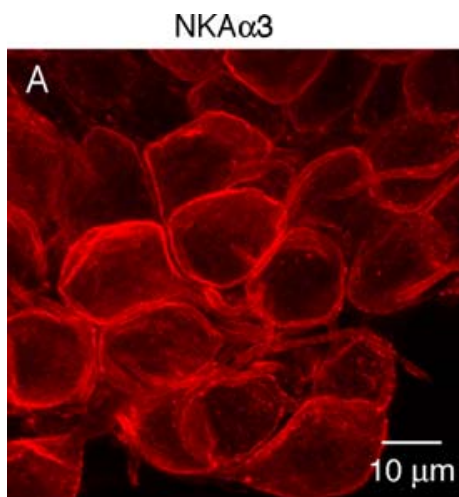

NKA $\alpha 3$

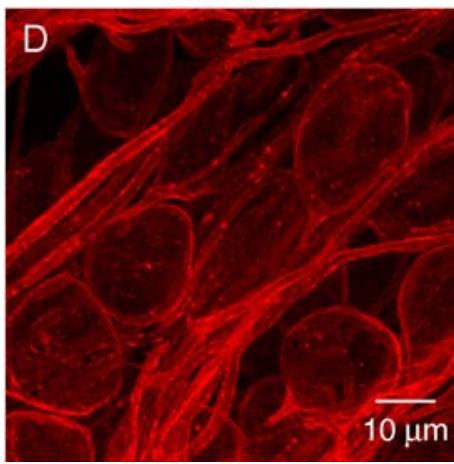

NF200

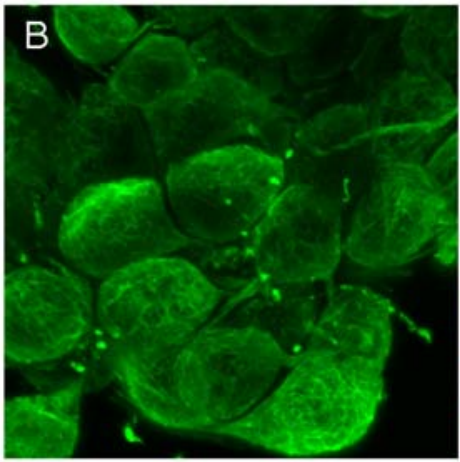

Peripherin

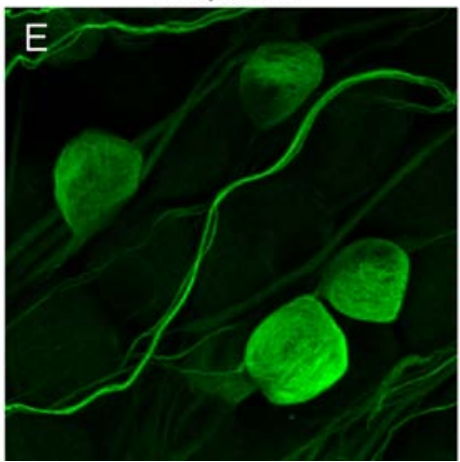

Merge

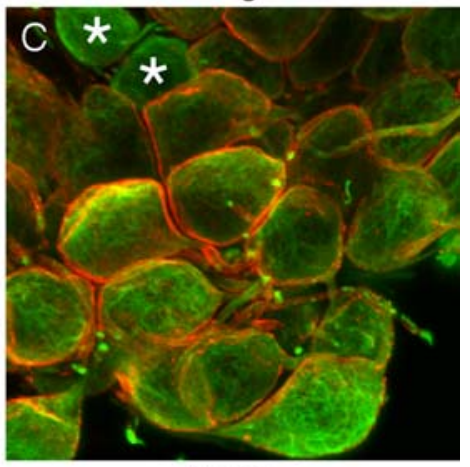

Merge

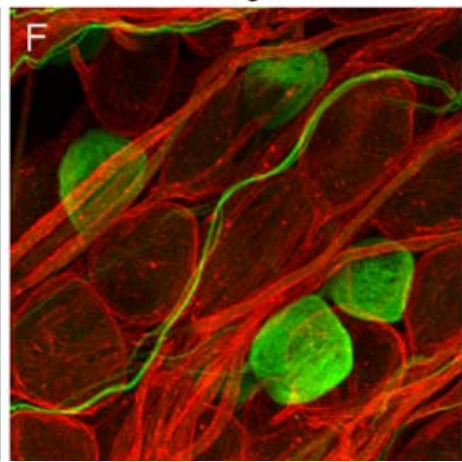

FIG. 2. NKA 3 is present in the type I but not type II spiral ganglion somata. High-magnification micrographs of apical cochlear turns double-labeled with a monoclonal anti-NKA 3 (red; A) and a polyclonal anti-NF200 (green; B) show that NKA 3 immunoreactivity is detected in the cell membranes of the majority of NF200-positive spiral ganglion somata $(\mathbf{C})$. To determine if the small population of

NKA $\alpha 3$ to the type I afferent terminals, organs of Corti were double-labeled with a monoclonal anti-NKA $\alpha 3$ and a polyclonal anti-NF200. These micrographs show membrane-bound NKA $\alpha 3$ immunoreactivity (red; Fig. 3D) surrounding cytoplasmic NF200 immunoreactivity (green; Fig. 3E) in the afferent terminal including its bouton-shaped tip (Fig. 3F). The patterns of NKA $\alpha 3$ immunoreactivity for calretinin-positive (Fig. 3A-C) and also NF200-positive fibers (Fig. 3D-F), in which NKA $\alpha 3$ immunoreactivity fully ensheathes the cytoplasmic markers, suggest that the type I afferent terminals express the NKA $\alpha 3$.

Previous work has shown that voltage-gated sodium channels in type I afferent fibers are localized at the heminode just before the first site of myelination and at subsequent unmyelinated nodes (Hossain et al. 2005). To determine if the region of greatest NKA $\alpha 3$ immunoreactivity corresponded to the initial unmyelinated segment of the type I afferent terminals, we double-labeled cochlear turns with a polyclonal antiNKA 33 (red) and a monoclonal antibody known to recognize all neuronal voltage-gated sodium channels, including those expressed in the cochlea (green; K58/35; Rasband et al. 1999). Indeed, NKA 23 immunoreactivity appears greatest in the initial unmyelin-
NKA 3 -negative spiral ganglion cells (marked with an asterisk; C) are, in fact, type II spiral ganglion somata, apical cochlear turns were double-labeled with a monoclonal anti-NKA 3 (red; D) and polyclonal anti-peripherin (green; E). Indeed, the cell membranes of the peripherin-positive, type II spiral ganglion somata do not show NKA 33 immunoreactivity $(\mathbf{F})$.

ated segment of the type I afferent fibers and does not overlap with the site of sodium channel enrichment in the first heminode (Fig. 3G). Although others have reported expression of the NKA $\alpha 3$ in the myelinated segments (Nakazawa et al. 1995) and nodes of Ranvier (Schulte and Adams 1989) of the afferent fibers, our experiments showed NKA $\alpha 3$ immunoreactivity that was most intense in the initial segments of the afferent fibers directly contacting the IHCs and not enriched in the subsequent unmyelinated nodes.

\section{$N K A \propto 3$ is not present in lateral olivocochlear efferents that contact the IHC afferent terminals}

Lateral olivocochlear efferent fibers make axodendritic synapses onto the unmyelinated terminals of type I afferent fibers close to where they contact the IHCs (Bergeron et al. 2005). To test whether NKA $\alpha 3$ immunoreactivity detected in the IHC region may also be due to expression of NKA $\alpha 3$ in lateral efferent fibers, we performed double labeling experiments with a monoclonal anti-NKA $\alpha 3$ and a polyclonal antisynapsin. Synapsin is known to label synaptic vesicle proteins found in the cytoplasm of traditional synapses (like the efferent synapses) but not in ribbon 
NKA $\alpha 3$

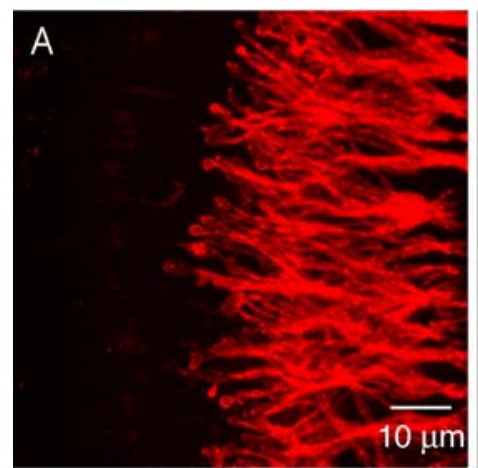

$\mathrm{NKA} \alpha 3$

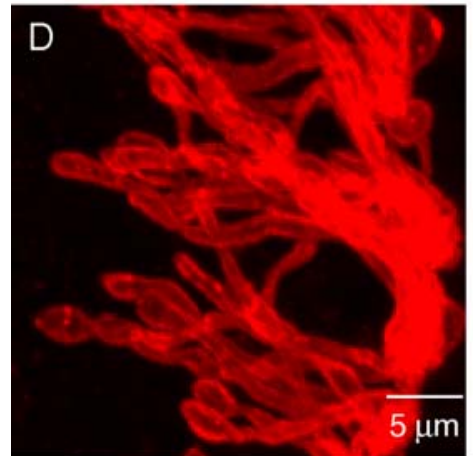

NKA $\alpha 3 /$ pan- $\mathrm{NaCh}$

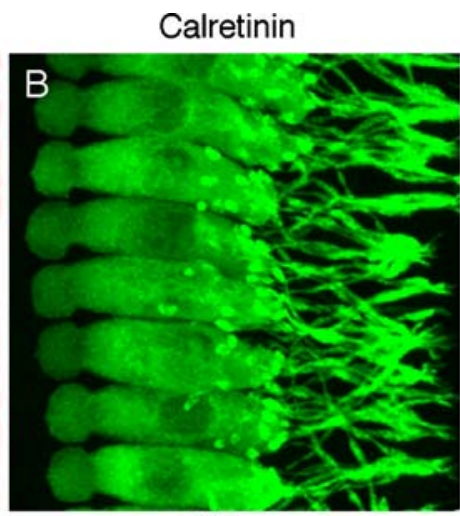

NF200

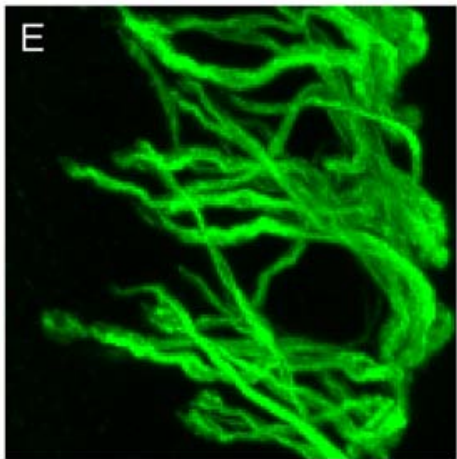

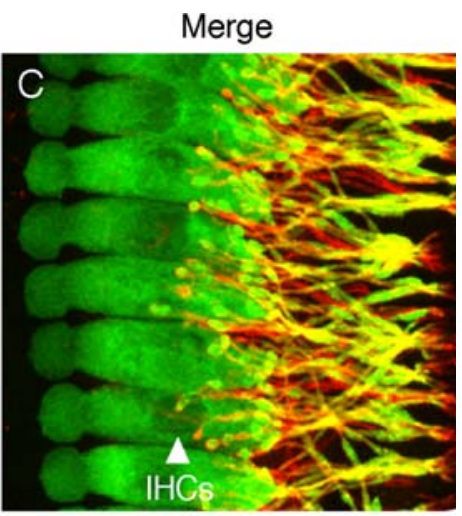

Merge

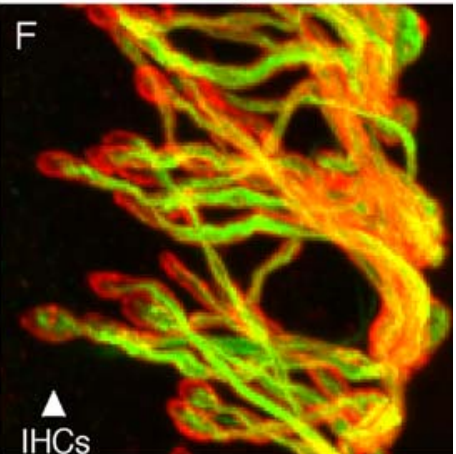

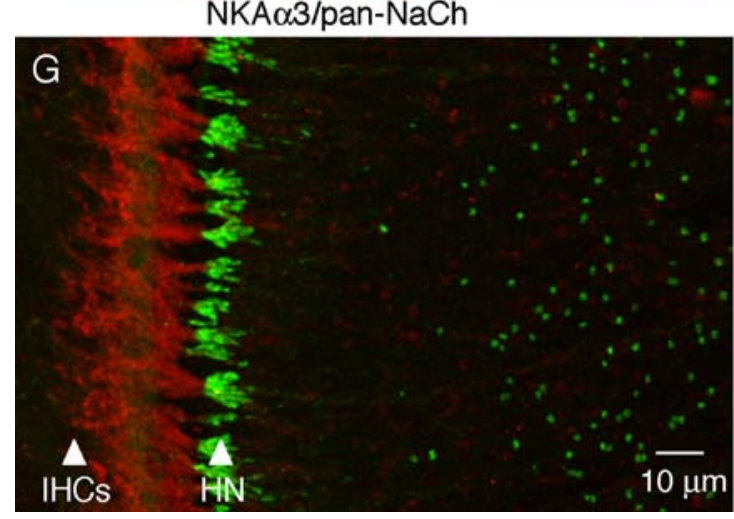

FIG. 3. NKA 33 is present in the type I afferent terminals. Highmagnification micrographs of apical cochlear turns double-labeled with a monoclonal anti-NKA 3 (red; A) and a polyclonal anti-calretinin (green; B) clearly show that the NKA $\alpha 3$-positive fibers are the type I afferent terminals that contact the inner hair cells (C). To further confirm expression of NKA 33 in the type I afferent terminals, apical cochlear turns were double-labeled with a monoclonal anti-NKA 3 (red; D) and a polyclonal anti-NF200 (green; E). NKA 33 immunoreactivity is indeed localized to the cell membranes and bouton-shaped endings of the NF200-expressing type I afferent terminals (F). To determine if NKA $\alpha 3$ -

synapses (von Kriegstein and Schmitz 2003). These double labeling experiments show that NKA $\alpha 3$-positive fibers to the IHCs (red; Fig. 4A) are contacted by synapsin-positive efferent presynapses (green; Fig. 4B) at their unmyelinated terminals (Fig. 4C). Importantly, NKA $\alpha 3$ immunoreactivity (red; Fig. 4A) does not ensheathe the efferent presynapses identified by their cytoplasmic synapsin labeling (green; Fig. 4B). Instead, synapsin-positive efferent presynapses appear to abut immunoreactivity was specifically restricted to the initial unmyelinated segments of the type I afferent terminals, apical cochlear turns were double-labeled with a polyclonal anti-NKA 3 (red) and a monoclonal pan anti-voltage-gated sodium channel (green). Micrographs show that NKA 33 immunoreactivity (red) is greatest just before and not overlapping with sites of sodium channel enrichment (green) at the heminode and is substantially less intense in the myelinated segments and subsequent unmyelinated nodes $(\mathbf{G})$. For orientation, the locations of the single row of inner hair cells (IHCs) and the first heminode (HN) have been indicated (with a triangle).

upon the membrane of the type I afferent fibers identified by their NKA $\alpha 3$ immunoreactivity (Fig. 4G). Because projections through the entire optical z-stack (Fig. 4) cannot be used to discriminate colocalization of objects above one another, single optical sections were used to examine the colocalization of synapsin-positive efferent presynapses that appeared colocalized with NKA $\alpha 3$-positive terminals (yellow in the z-projections shown in Fig. 4C). Analysis of series of single optical 
sections (data not shown) confirmed that NKA $\alpha 3$ immunoreactivity does not colocalize with or ensheathe the lateral efferent terminals identified by their cytoplasmic labeling for synapsin. Thus, this pattern of immunoreactivity, in which efferent presynapses labeled cytoplasmically with synapsin do not show membranebound NKA $\alpha 3$ immunoreactivioty, is consistent with the axodendritic contacts formed between the lateral efferents and type I afferent terminals and suggests that NKA $\alpha 3$ expression is restricted to the type I afferent terminals.

\section{$N K A \alpha 3$ is present in medial olivocochlear efferents that contact the OHCs}

To further investigate the expression of the NKA $\alpha 3$ in fibers contacting the OHCs, double labeling experiments with antibodies against the NKA $\alpha 3$ and other established markers of structures in the $\mathrm{OHC}$ region were performed. Double labeling of organs of Corti with a monoclonal anti-NKA 23 (red; Fig. 5A) and a polyclonal anti-prestin (green; Fig. 5B), a protein enriched in the cell membrane (especially lateral walls) of the OHCs (Belyantseva et al. 2000), shows the NKA $\alpha$-positive fibers traveling through the tunnel of Corti and contacting the three rows of OHCs with their bouton-shaped terminals (Fig. 5C). Double labeling with a monoclonal anti-NKA $\alpha 3$ (red; Fig. 5D) and a polyclonal anti-synapsin (green; Fig. 5E) show that NKA $\alpha 3$ and synapsin immunoreactivity are localized to the same set of terminals (Fig. 5F). Higher magnification micrographs clearly show membrane-bound NKA 33 immunoreactivity (Fig. 5G) completely ensheathing cytoplasmic synapsin immunoreactivity (Fig. $5 \mathrm{H}$ ) in the bouton-shaped terminals contacting the OHCs (Fig. 5I). The known expression of synapsin in the efferent presynapses identifies these NKA $\alpha 3$-positive fibers as the medial efferent fibers that innervate the OHCs.

\section{NKA 3 is absent in type II afferent fibers that contact the $\mathrm{OHCs}$}

Double labeling experiments were performed to test whether NKA $\alpha 3$ immunoreactivity detected in the $\mathrm{OHC}$ region may also be due to expression of the NKA $\alpha 3$ in the type II afferent fibers that contact the OHCs. Double labeling experiments with a monoclonal anti-NKA $\alpha 3$ (red; Fig. 6A) and a polyclonal anti-NF200 (green; Fig. 6B) show distinct, non-overlapping patterns of immunoreactivity for the NKA $\alpha 3$-positive fibers and the NF200-positive fibers that appear in the outer spiral bundles under the OHCs (Fig. 6C). This lack of colocalization is better viewed in the $x$-axis cross-section through the z-projection, which reveals that the NKA $\alpha 3$ positive fibers (red; Fig. 6D) are located in a separate plane compared to the NF200-positive fibers (green; Fig. 6E, F). Similar results were found when double labeling with a monoclonal anti-NKA $\alpha 3$ and a polyclonal anti-peripherin (data not shown). Together, these experiments suggest that the NKA $\alpha 3$ is not expressed in type II afferent fibers that contact the OHCs.

NKA $\alpha 1$ is present in supporting cells surrounding the IHCs

To determine if other isoforms of the NKA $\alpha$ are also expressed in the neuronal structures of the organ of Corti, we immunolabeled apical cochlear turns with various antibodies against NKA $\alpha 1$ and NKA $\alpha 2$. No immunoreactivity was detected for either of two antibodies used against the NKA $\alpha 2$ (sc-16049 and
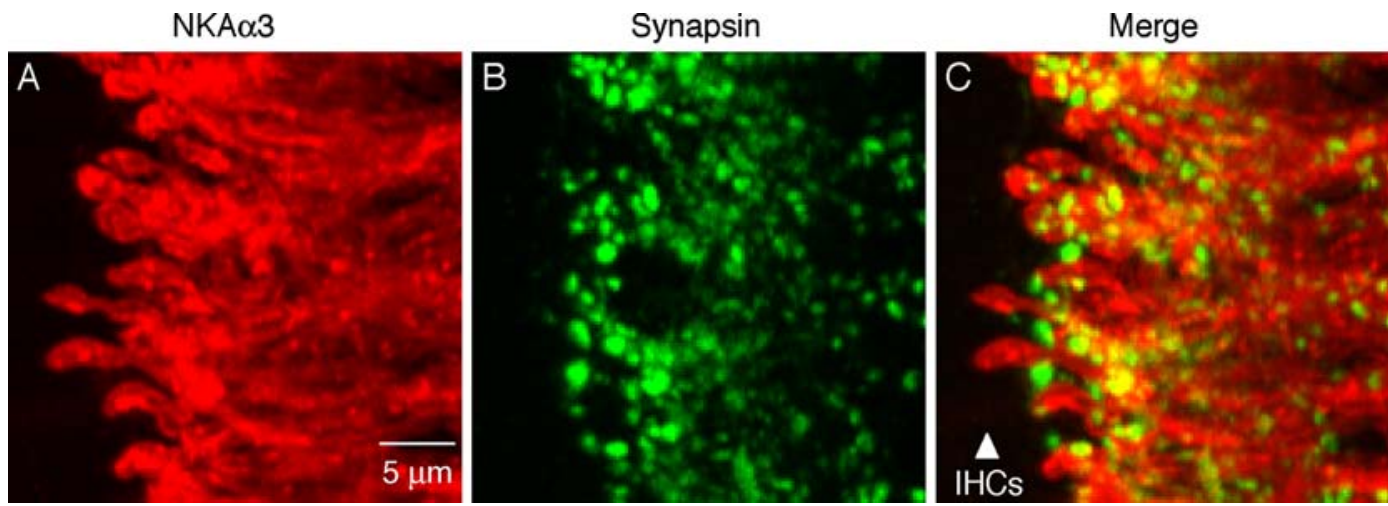

FIG. 4. NKA $\alpha 3$ is not present in the lateral olivocochlear efferent fibers. Lateral olivocochlear efferent fibers make axodendritic synapses onto the unmyelinated terminals of type I afferent fibers close to where they contact the inner hair cells. To determine if these lateral efferent fibers express the NKA 33 , apical cochlear turns were double-labeled with a monoclonal anti-NKA 33 (red; A) and a polyclonal anti-synapsin (green; B). These experiments show that the NKA 3 3-positive terminals (red) are, in fact, contacted by the synapsin-expressing efferent terminals (green) extracellularly $(\mathbf{C})$. This pattern of immunoreactivity is consistent with the axodendritic contacts formed between the lateral efferents and type I afferent terminals and suggests that NKA $\alpha 3$ expression is restricted to the type I afferent terminals. For orientation, the location of the single row of inner hair cells (IHCs) has been indicated (with a triangle). 


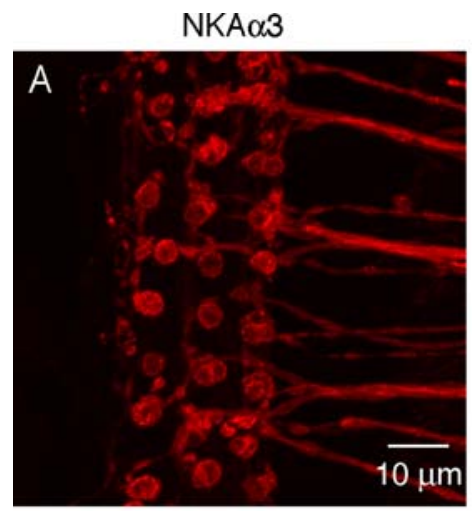

NKA $\alpha 3$
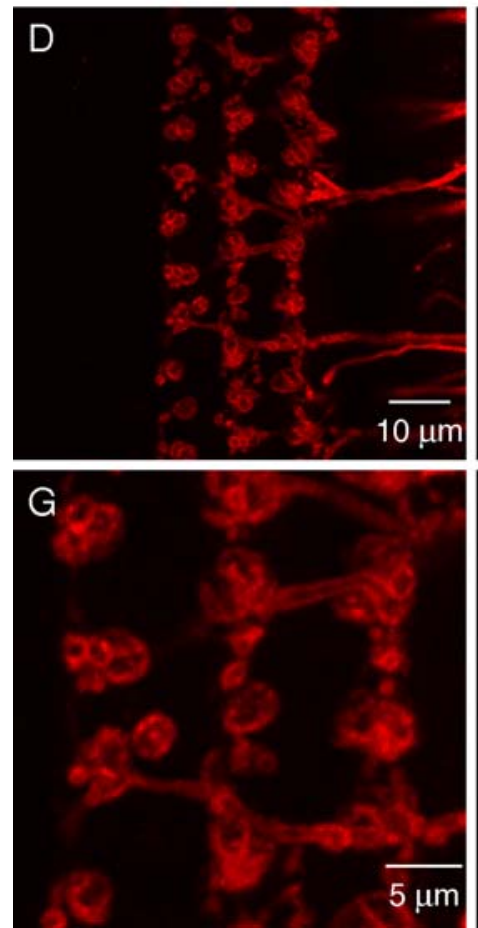

Prestin

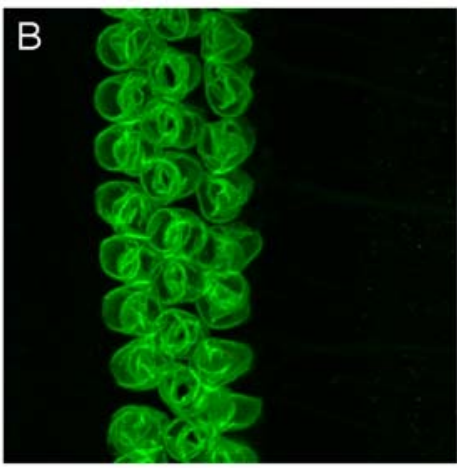

Synapsin
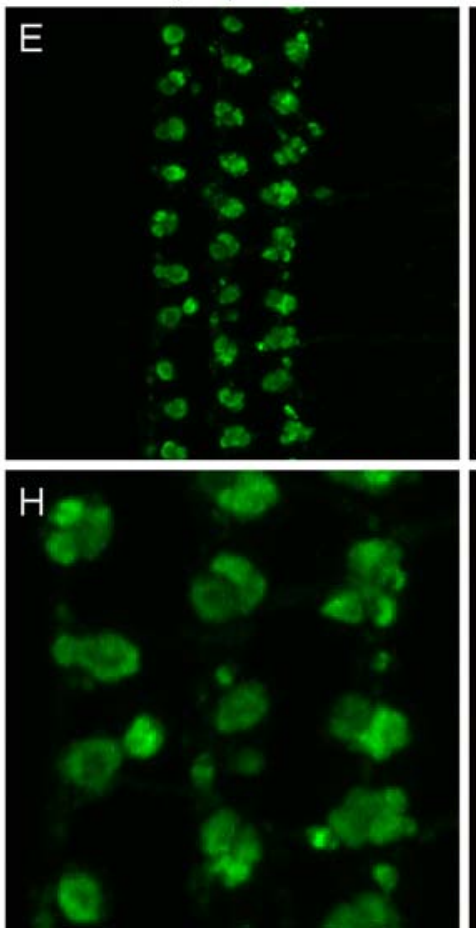

Merge

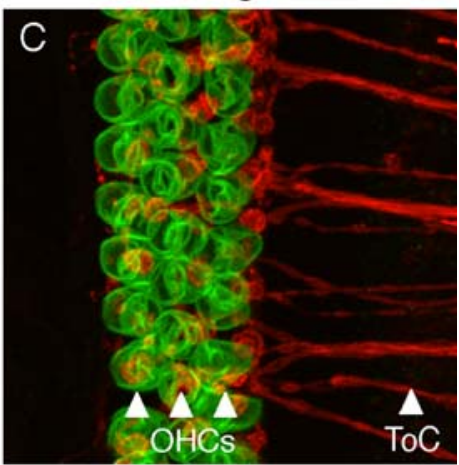

Merge
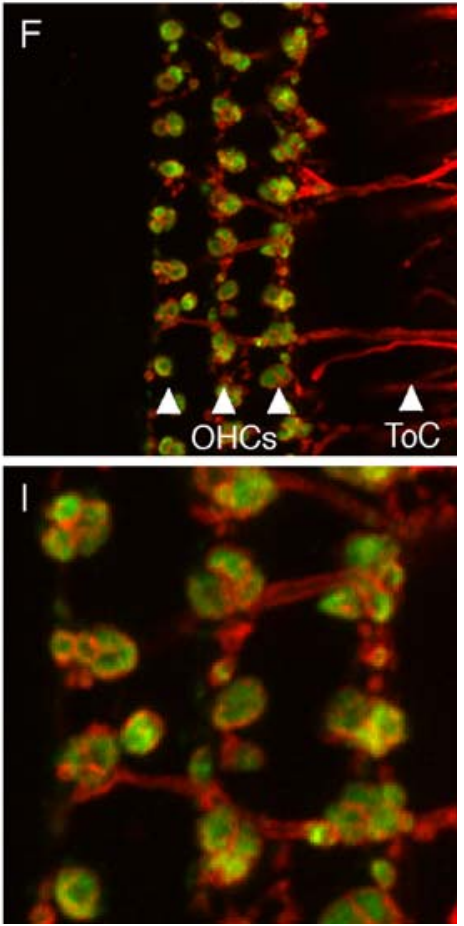

FIG. 5. NKA $\alpha 3$ is present in the medial efferent fibers. Double labeling of apical cochlear turns with a monoclonal anti-NKA 23 (red; A) and a polyclonal anti-prestin (green; B) shows that NKA 33 positive fibers contact the three rows of outer hair cells $(\mathbf{C})$. To identify these fibers, double labeling experiments were performed with a monoclonal anti-NKA $\alpha 3$ (red; D) and a polyclonal antisynapsin (green; E). These experiments show that NKA 33 and synapsin immunoreactivity are localized to the same set of

anti-HERED, data not shown). Interestingly, both monoclonal antibodies used against the NKA $\alpha 1$ showed patterns of immunoreactivity that were distinct from that seen for the NKA $\alpha 3$. Double labeling of organs of Corti with a monoclonal NKA $\alpha 1$ (C464.6; red; Fig. 7A) and a polyclonal anti-NKA $\alpha 3$ (green; Fig. 7B) show NKA $\alpha 1$ immunoreactivity in the IHC region that does not overlap with the NKA $\alpha 3$-positive type I afferent fibers that contact the IHCs (Fig. 7C). Subsequent double labeling experiments with a monoclonal anti-NKA $\alpha 1$ (C464.6; red, Fig. 7D) and a polyclonal anti-calretinin (green, Fig. 7E) show that terminals (F). Higher magnification micrographs clearly show membrane-bound NKA 33 immunoreactivity (red; G) surrounding cytoplasmic synapsin immunoreactivity (green; $\mathbf{H}$ ) in the boutonshaped terminals contacting the outer hair cells (I). Together, these experiments identify the NKA 33 -positive fibers targeting the OHCs as the medial efferent fibers. For orientation, the location of the three rows of outer hair cells (OHCs) and the tunnel of Corti (ToC) have been indicated (with a triangle).

NKA $\alpha 1$ immunoreactivity is specific to supporting cells surrounding the calretinin-positive IHCs, including the inner phalangeal cells that separate the IHCs (Fig. 7F). Inner phalangeal cells, in addition to closely neighboring supporting cells, are known to express the glutamate transporter GLAST and are thought to take up glutamate released from the IHCs (Furness and Lehre 1997; Hakuba et al. 2000; Furness and Lawton 2003; Glowatzki et al. 2006). To determine if the NKA $\alpha 1$-positive cells in the IHC region include the GLAST-expressing inner phalangeal cells, we performed double labeling experiments with a mono- 
NKA $\alpha 3$
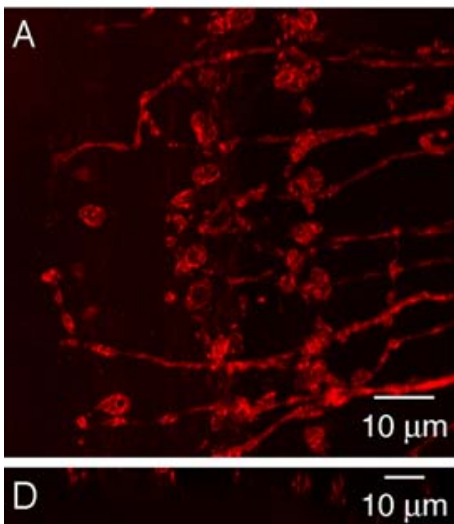

NF200

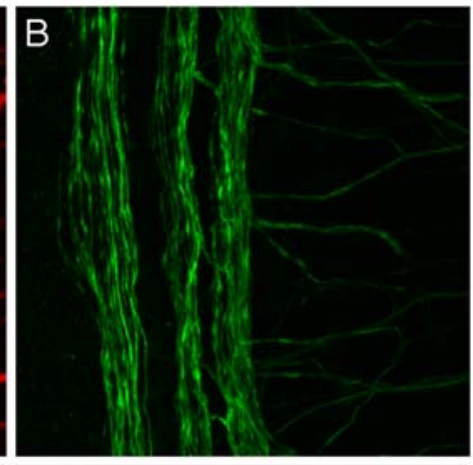

$E$

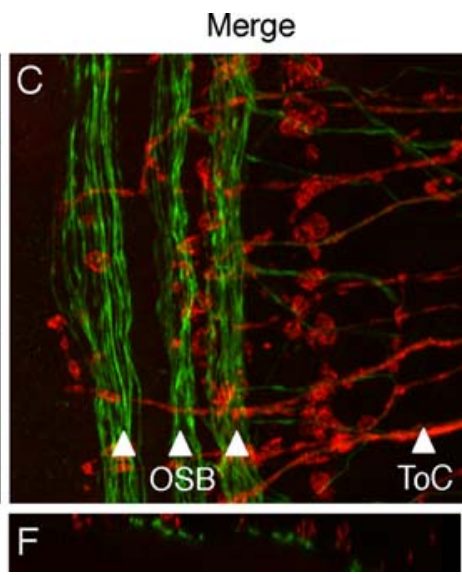

FIG. 6. NKA $\alpha 3$ is not present in the type II afferent fibers. To determine if NKA $\alpha$-immunoreactivity detected in the outer hair cell region may also be due to expression of the NKA $\alpha 3$ in the type II afferent fibers that contact the outer hair cells, double labeling of apical cochlear turns with a monoclonal anti-NKA 33 (red; A) and a polyclonal anti-NF200 (green; B) was performed. High-magnification micrographs show that the NKA $\alpha 3$-positive fibers are distinct from the NF200-positive fibers that form the outer spiral bundles under the

clonal anti-NKA $\alpha 1$ (C464.6; red, Fig. 7G) and a polyclonal anti-GLAST (green, Fig. 7H). The overlapping patterns of NKA $\alpha 1$ and GLAST immunoreactivity (Fig. 7I) suggest that the NKA $\alpha 1$ is also expressed by the GLAST-positive inner phalangeal cells and other supporting cells that surround the IHCs.

\section{DISCUSSION}

The aim of this study was to characterize the neuronal expression of NKA $\alpha$ in the organ of Corti and spiral ganglion. Compared to earlier work, our study utilized double immunofluorescent labeling and higher resolution micrographs of whole-mount preparations of the rat cochlea to unambiguously assign NKA $\alpha$ immunoreactivity to specific subtypes and subcellular structures of neurons. We identified NKA $\alpha 3$ in the somata and postsynaptic afferent terminals of type I SGNs that contact the IHCs and in the presynaptic medial efferent terminals that contact the OHCs. No NKA $\alpha 3$ immunoreactivity was detected in type II SGNs that contact the OHCs or in the lateral efferent terminals that contact the type I afferent terminals. Thus, NKA 33 expression appears restricted to the myelinated nerve fibers of the cochlea. Such somatic, axonal, and dendritic expression of NKA $\alpha 3$ has been reported in a variety of preparations (reviewed in Dobretsov and Stimers 2005). Thus, there does not seem to be a particular subcellular compartment to which NKA $\alpha 3$ expression is restricted in either the central or peripheral nervous system. outer hair cells $(\mathbf{C})$. This lack of colocalization is better viewed in the $x$-axis cross section through the z-projection, which reveals that the NKA 3 -positive fibers (red; D) relative to the NF200-positive fibers (green; E) are located in a separate plane $(\mathbf{F})$. These results suggest that the NKA 3 is not expressed in type II afferent fibers that contact the outer hair cells. For orientation, the location of the three rows of the outer spiral bundle (OSB) and the tunnel of Corti (ToC) have been indicated (with a triangle).

Our findings are consistent with earlier research using immunocytochemistry that identified the NKA $\alpha 3$ in the SGNs and cochlear nerve in the gerbil (Schulte and Adams 1989; McGuirt and Schulte 1994; Nakazawa et al. 1995), rat (ten Cate et al. 1994; Peters et al. 2001), and mouse (Erichsen et al. 1996). NKA $\alpha$ immunoreactivity was localized to the nerve terminals underlying the IHCs and OHCs in the human cochlea (Weber et al. 2001). Ultrastructural analysis attributed NKA $\alpha$ immunoreactivity in the terminals underlying the IHCs to the type I afferent and not lateral efferent terminals in the gerbil (Nakazawa et al. 1995). Additional work has shown that NKA $\alpha$ immunoreactivity in the terminals underlying the IHCs and OHCs is due to expression of the NKA $\alpha 3$ in both the gerbil (Schulte and Adams 1989; McGuirt and Schulte 1994) and rat (ten Cate et al. 1994).

We also tested for the presence of the other NKA $\alpha$ isoforms in the organ of Corti and spiral ganglion. We found NKA $\alpha 1$ in supporting cells surrounding the IHCs (see discussion below). We found no NKA $\alpha 1$ immunoreactivity in the afferent terminals. Previous studies have reported weak to moderate NKA $\alpha 1$ immunoreactivity in the SGNs and cochlear nerve of the rat (ten Cate et al. 1994; Peters et al. 2001; Delprat et al. 2007) and mouse (Erichsen et al. 1996), and one study reports expression of the NKA $\alpha$ in the afferent terminals underlying the OHCs in the gerbil (Nakazawa et al. 1995). Although we did not find NKA $\alpha 1$ immunoreactivity in either type I or II afferent terminals, we did see NKA $\alpha 1$ labeling in the spiral ganglion (data not shown) but were unable to identify unequivocally the NKA $\alpha 1$-expressing cells as either the SGNs or ensheathing satellite cells. In the region of the spiral ganglion, 
NKA $\alpha 1$

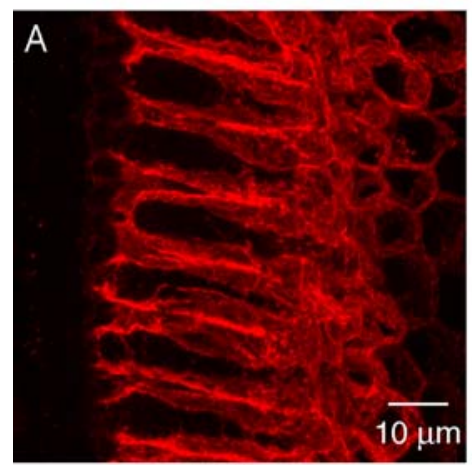

NKA $\alpha 1$

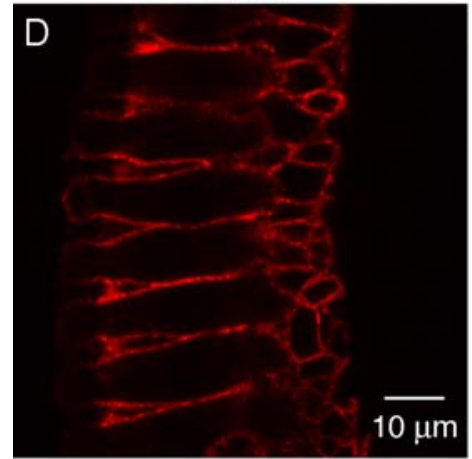

NKA $\alpha 1$

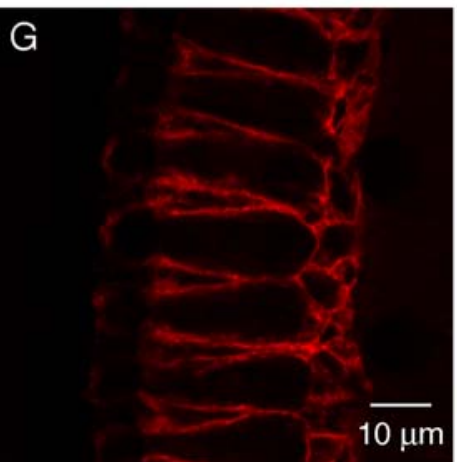

FIG. 7. NKA 1 is present in the GLAST-expressing inner phalangeal and supporting cells of the organ of Corti. Double labeling of apical cochlear turns with a monoclonal anti-NKA 1 (red; A) and a polyclonal anti-NKA 3 (green; B) show NKA $\alpha 1$ immunoreactivity in the IHC region that does not overlap with the NKA 3 -positive type I afferent terminals that contact the IHCs (C). Subsequent double labeling experiments with a monoclonal anti-NKA 1 (red; D) and a polyclonal anti-calretinin (green; E) show that NKA 1 immunoreactiv-

NKA $\alpha 1$ immunoreactivity in the gerbil cochlea (McGuirt and Schulte 1994; Schulte and Steel 1994) and NKA $\alpha$ immunoreactivity in the human cochlea (Weber et al. 2001) were attributed to the satellite cells. We were unable to detect NKA $\alpha 2$ immunoreactivity in the organ of Corti or spiral ganglion with either of two antibodies used (data not shown). While some groups have reported exclusive expression of the NKA $\alpha 2$ in the supralimbal fibrocytes (McGuirt and Schulte 1994; Schulte and Steel 1994; Peters et al. 2001), others have reported additional weak or transient NKA $\alpha 2$ immuno-
NKA $\alpha 3$

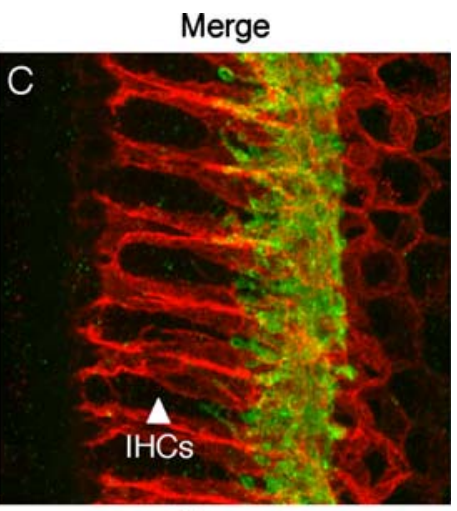

Calretinin
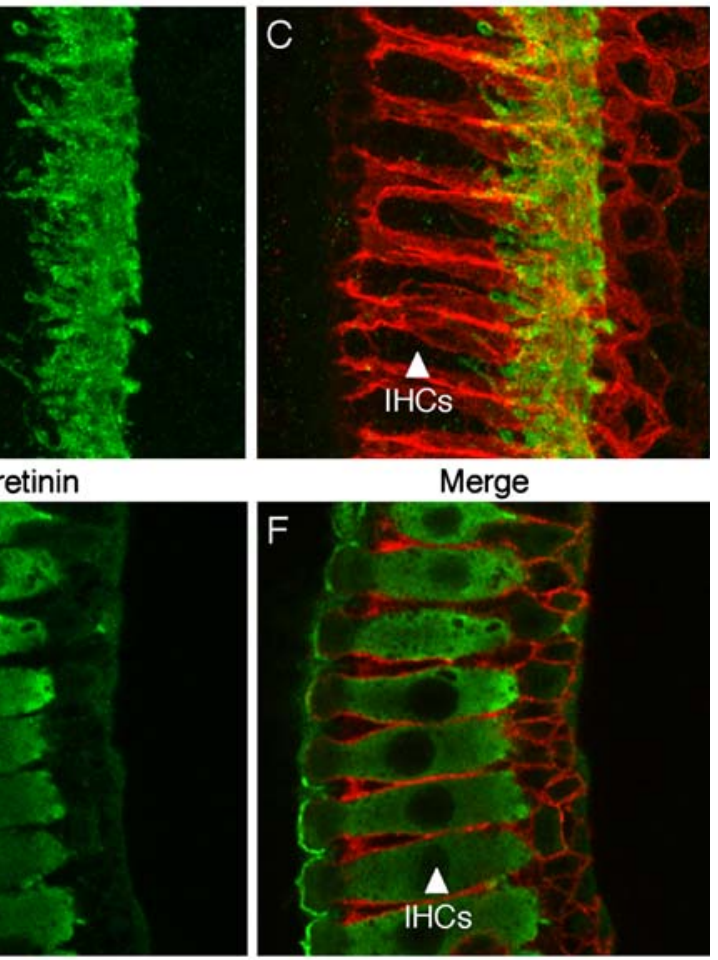

GLAST

Merge

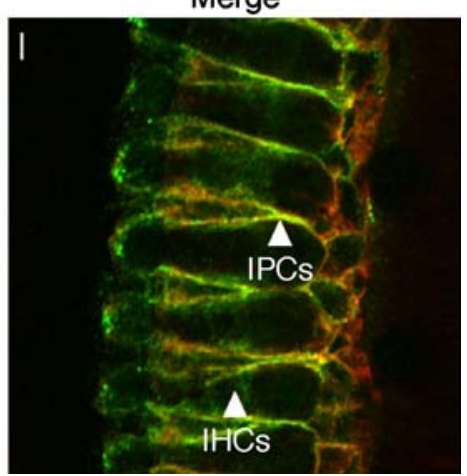

ity is specific to cells surrounding and separating the calretinin-positive IHCs (F). The similar patterns of immunoreactivity seen in double labeling experiments with a monoclonal anti-NKA 1 (red; G) and a polyclonal anti-GLAST (green; $\mathbf{H}$ ) identify the NKA $\alpha 1$-positive cells in the IHC region as the GLAST-expressing inner phalangeal and supporting cells of the organ of Corti (I). For orientation, the location of the inner phalangeal cells (IPCs) and single row of inner hair cells (IHCs) has been indicated (with a triangle).

reactivity in the cochlear nerve (ten Cate et al. 1994; Erichsen et al. 1996).

Our results suggest that the myelinated nerve fibers of the organ of Corti express only NKA $\alpha 3$. Although NKA $\alpha 1$ is often considered to be ubiquitously expressed, the exclusive expression of NKA $\alpha 3$ has been observed in a variety of neurons (McGrail et al. 1991) including those that maintain tonic and/or rapid rates of firing, such as the afferent and efferent nerve fibers innervating the muscle stretch receptor (Dobretsov et al. 2003), neurons of the rat medial 
geniculate nucleus in auditory thalamus (Senatorov et al. 1997), as well as the calyx of Held afferent terminals in the medial nucleus of the trapezoid body in auditory brainstem (Kim et al. 2007). The selective expression of NKA $\alpha 3$ provides unique insight into the physiological demands on the myelinated fibers in the cochlea. The NKA $\alpha 3$ is distinguished from the NKA $\alpha 1$ by its relatively low affinity for intracellular sodium (Jewell and Lingrel 1991; Munzer et al. 1994; Zahler et al. 1997; Crambert et al. 2000), high affinity for ATP (Jewell and Lingrel 1991), and lack of inhibition at hyperpolarized potentials (Balshaw et al. 2000; Crambert et al. 2000). Thus, NKA $\alpha 3$ may be especially suited for the myelinated fiber types of the cochlea that sustain high rates of activity that would be expected to raise intracellular sodium concentrations, deplete ATP, and maintain hyperpolarized membrane potentials. In fact, the NKA $\alpha 1$ isoform, which has a much steeper voltage dependence of its transport rate compared to the NKA $\alpha 3$ isoform, may respond too quickly to action potential depolarization and prevent sustained firing (Dobretsov and Stimers 2005).

In testing for other NKA $\alpha$ isoforms in the organ of Corti, we found NKA $\alpha 1$ immunoreactivity in the gliallike supporting cells surrounding the IHCs, including the inner phalangeal cells. Previous ultrastructural work reported NKA $\alpha 1$ immunoreactivity of the inner phalangeal and border cells in rat (Iwano et al. 1990). These supporting cells express the glutamate transporter GLAST and are thought to remove glutamate from the extracellular space that has been released from the IHC (Furness and Lehre 1997; Hakuba et al. 2000; Furness and Lawton 2003; Glowatzki et al. 2006). The expression of NKA $\alpha 1$ in these supporting cells is not unexpected: glutamate transporters rely on sodium gradients to transport glutamate (Danbolt 2001). The NKA $\alpha$ inhibitors ouabain and vanadate have been shown to block the clearance of extracellular glutamate in cultured rat cortical astrocytes, suggesting that glutamate transporters are dependent on NKA $\alpha$ activity (Abe and Saito 2000). Our experiments suggest that GLAST-mediated glutamate uptake by the supporting cells adjacent to IHCs may be dependent upon the activity of NKA $\alpha 1$.

Our knowledge about the functional involvement of the NKA $\alpha$ in hearing has come from experiments involving inhibitors of the NKA $\alpha$ and also from experiments using mice with genetic deletions of the NKA $\alpha$. Perilymphatic perfusion of ouabain, an inhibitor of the NKA $\alpha$, causes a rapid reduction of the endocochlear potential (Konishi and Mendelsohn 1970; Kuijpers and Bonting 1970; Kusakari et al. 1978), and researchers have identified NKA $\alpha 1$ in the strial marginal cells and NKA $\alpha 2$ in the lateral wall fibrocytes (McGuirt and Schulte 1994; Schulte and Steel 1994; reviewed in Wangemann 2006). The contribution of the NKA $\alpha 1$ and NKA $\alpha 2$ in maintaining the endocochlear potential is supported by the characterization of mice carrying deletions of these subunits. Although homozygous deletion of either NKA $\alpha 1$ or NKA $\alpha 2$ is lethal at birth, heterozygous deletions are viable (Moseley et al. 2007). Despite normal cochlear morphology, NKA $\alpha 1^{+/-}$and $\mathrm{NKA} \alpha 2^{+/-}$mice show reductions in the endocochlear potential and progressive, age-dependent hearing loss (Diaz et al. 2007). A possible neuronal contribution to hearing loss in these mice has not been excluded.

The contribution of the NKA $\alpha 3$ to hearing is less obvious. Homozygous deletion of NKA $\alpha 3$ is lethal; however, heterozygous deletion is viable (Moseley et al. 2007). The hearing of $\mathrm{NKA} 3^{+/-}$mice has not been reported. More recent studies investigating the perfusion of ouabain directly through the round window of the gerbil cochlea provide evidence for an additional neuronal role of the NKA $\alpha$ in the cochlea. Specifically, these experiments show threshold increases or complete abolishment of the compound action potential without a reduction of the endocochlear potential (Schmiedt et al. 2002; Wang et al. 2006). Moreover, chronic exposure to ouabain is associated with degeneration of type I but not type II SGNs in the gerbil cochlea (Lang et al. 2005). These findings are consistent with our observation of the NKA $\alpha 3$ in type I but not type II spiral ganglion afferent terminals. Especially in rodents, the NKA $\alpha 3$ isoform is much more sensitive to inhibition by ouabain than the NKA $\alpha 1$ isoform and slightly more sensitive than the NKA $\alpha 2$ isoform (O'Brien et al. 1994). Thus, specific doses of ouabain could be expected to inhibit the NKA $\alpha 3$ isoform and reduce or abolish the compound action potential without necessarily affecting the NKA $\alpha 1$-and NKA $\alpha 2$-dependent endocochlear potential.

The expression pattern of the NKA $\alpha$ in the organ of Corti and spiral ganglion suggests that both the NKA $\alpha 1$ and NKA $\alpha 3$ are poised to play an essential role in the regulation of the type I afferent synapses, the medial efferent synapses, and also glutamate transport from the afferent-IHC synapse. Thus, in addition to maintaining the endocochlear potential, the NKA $\alpha$ may contribute directly to the functioning of these synapses in the inner ear. Future investigation of the particular $\beta$ (1-3) and FXYD (1-7) subunits coexpressed with the NKA $\alpha 1$ and NKA $\alpha 3$ will identify the additional molecular players involved in tailoring the NKA $\alpha$ transport properties at each of these synapses. Ultimately, clarifying the molecular components and neuronal contribution of the NKA in the cochlea will suggest ways in which its activity may be altered by exogenous inhibitors as a possible means to treat hearing loss (Aperia 2007) and also, very excitingly, by naturally occurring, endogenously 
expressed inhibitors (Nesher et al. 2007; Schoner and Scheiner-Bobis 2007) that may contribute to both normal and pathological hearing states.

\section{ACKNOWLEDGMENTS}

We would like to thank Mr. D. Mark Gay and Dr. Richard Dillaman at the University of North Carolina at Wilmington for excellent assistance with confocal microscopy, Dr. Paul A. Fuchs at the Johns Hopkins University for scientific advice and comments on the manuscript, Dr. Richard W. Aldrich at the University of Texas at Austin for supporting the preliminary experiments performed in his laboratory then at Stanford University, and Dr. Kathleen J. Sweadner at the Massachusetts General Hospital and the Harvard Medical School for advice and recommendations regarding antibodies against the Na,K-ATPase. The $\alpha 6 \mathrm{~F}$ monoclonal antibody developed by Dr. Douglas Fambrough was obtained from the Developmental Studies Hybridoma Bank developed under the auspices of the National Institute of Child Health and Human Development and maintained by the University of Iowa, Department of Biological Sciences, Iowa City, IA 52242. The monoclonal antibody anti-HERED was generously provided by Dr. Thomas Pressley at the Texas Tech University. The monoclonal antibody K58/23 was generously provided by Dr. James Trimmer at the University of California at Davis. This work was supported by National Institute of Deafness and Communication Disorders grants (DC00276 to Dr. Paul Fuchs and DC006476 to E. G.), a research award from the National Organization for Hearing Research (to S. J. P), a new investigator research award from the American Academy of Audiology (to S. J. P.) and a research grant from the Deafness Research Foundation (to S. J. P.).

\section{REFERENCES}

AвE K, SAito $\mathrm{H}$. Involvement of $\mathrm{Na}+\mathrm{K}+$ pump in L-glutamate clearance by cultured rat cortical astrocytes. Biol. Pharm. Bull. 23:1051-1054, 2000.

APERIA A. New roles for an old enzyme: Na,K-ATPase emerges as an interesting drug target. J. Intern. Med. 261:44-52, 2007.

Arystarkhova E, Sweadner KJ. Isoform-specific monoclonal antibodies to Na,K-ATPase alpha subunits. Evidence for a tissuespecific post-translational modification of the alpha subunit. J. Biol. Chem. 271:23407-23417, 1996.

Balshaw DM, Millette LA, Tepperman K, Wallick ET. Combined allosteric and competitive interaction between extracellular $\mathrm{Na}(+)$ and $\mathrm{K}(+)$ during ion transport by the alpha(1), alpha(2), and alpha(3) isoforms of the Na, K-ATPase. Biophys. J. 79:853-862, 2000.

Belyantseva ia, Adler HJ, Curi R, Frolenkov Gi, Kachar B. Expression and localization of prestin and the sugar transporter GLUT-5 during development of electromotility in cochlear outer hair cells. J. Neurosci. 20:RC116, 2000.

Bergeron AL, Schrader A, Yang D, Osman AA, Simmons DD. The final stage of cholinergic differentiation occurs below inner hair cells during development of the rodent cochlea. J. Assoc. Res. Otolaryngol. 6:401-415, 2005.
Berglund AM, Rrugo DK. Neurofilament antibodies and spiral ganglion neurons of the mammalian cochlea. J. Comp. Neurol. 306:393-408, 1991.

Blanco G. Na,K-ATPase subunit heterogeneity as a mechanism for tissue-specific ion regulation. Semin. Nephrol. 25:292-303, 2005.

Crambert G, Hasler U, Beggah AT, Yu C, Modyanov NN, Horisberger JD, Lelievre L, Geering K. Transport and pharmacological properties of nine different human Na, K-ATPase isozymes. J. Biol. Chem. 275:1976-1986, 2000.

Danbolt NC. Glutamate uptake. Prog. Neurobiol. 65:1-105, 2001.

Dechesne CJ, Winsky L, Kim HN, Goping G, Vu TD, Wenthold RJ, JACoвowITz DM. Identification and ultrastructural localization of a calretinin-like calcium-binding protein (protein 10) in the guinea pig and rat inner ear. Brain Res. 560:139-148, 1991.

Dechesne CJ, Winsky L, Moniot B, Raymond J. Localization of calretinin mRNA in rat and guinea pig inner ear by in situ hybridization using radioactive and non-radioactive probes. Hear. Res. 69:91-97, 1993.

Delprat B, Puel JL, Geering K. Dynamic expression of FXYD6 in the inner ear suggests a role of the protein in endolymph homeostasis and neuronal activity. Dev. Dyn. 236:2534-2540, 2007.

Diaz RC, Vazquez AE, Dou H, Wei D, Cardell El, Lingrel J, Shull GE, Doyle KJ, YAMOAH EN. Conservation of hearing by simultaneous mutation of Na,K-ATPase and NKCC1. J. Assoc. Res. Otolaryngol. 8:422-434, 2007.

Dobretsov M, Stimers JR. Neuronal function and alpha3 isoform of the Na/K-ATPase. Front Biosci. 10:2373-2396, 2005.

Dobretsov M, Hastings SL, Sims TJ, Stimers JR, Romanovsky D. Stretch receptor-associated expression of alpha 3 isoform of the $\mathrm{Na}+\mathrm{K}+$-ATPase in rat peripheral nervous system. Neuroscience 116:1069-1080, 2003.

Erichsen S, Zuo J, Curtis L, Rarey K, Hultcrantz M. Na,K-ATPase alpha-and beta-isoforms in the developing cochlea of the mouse. Hear. Res. 100:143-149, 1996.

Fuchs PA, Glowatzki E, Moser T. The afferent synapse of cochlear hair cells. Curr. Opin. Neurobiol. 13:452-458, 2003.

Furness DN, Lawton DM. Comparative distribution of glutamate transporters and receptors in relation to afferent innervation density in the mammalian cochlea. J. Neurosci. 23:11296-11304, 2003.

FURNESS DN, LEHRE KP. Immunocytochemical localization of a highaffinity glutamate-aspartate transporter, GLAST, in the rat and guinea-pig cochlea. Eur. J. Neurosci. 9:1961-1969, 1997.

GEERING K. Function of FXYD proteins, regulators of Na, K-ATPase. J. Bioenerg. Biomembr. 37:387-392, 2005.

Glowatzki E, Cheng N, Hiel H, Yi E, Tanaka K, Ellis-Davies GC, Rothstein JD, Bergles DE. The glutamate-aspartate transporter GLAST mediates glutamate uptake at inner hair cell afferent synapses in the mammalian cochlea. J. Neurosci. 26:7659-7664, 2006.

Groff JA, Liberman MC. Modulation of cochlear afferent response by the lateral olivocochlear system: activation via electrical stimulation of the inferior colliculus. J. Neurophysiol. 90:31783200, 2003.

Guinan J. Physiology of olivocochlear efferents. In: Dallos P, Popper AN, Fay RR (eds) The cochlea. New York, Springer, pp. 435-502, 1996.

HAFIDI A. Peripherin-like immunoreactivity in type II spiral ganglion cell body and projections. Brain Res. 805:181-190, 1998.

Hakuba N, Koga K, Gyo K, Usami SI, Tanaka K. Exacerbation of noise-induced hearing loss in mice lacking the glutamate transporter GLAST. J. Neurosci. 20:8750-8753, 2000.

Hossain WA, Antic SD, Yang Y, Rasband MN, Morest DK. Where is the spike generator of the cochlear nerve? Voltage-gated sodium channels in the mouse cochlea. J. Neurosci. 25:6857-6868, 2005.

Iwano T, Yamamoto A, Omori K, Kawasaki K, Kumazawa T, Tashiro Y. Quantitative immunogold localization of $\mathrm{Na}+\mathrm{K}(+)$-ATPase 
alpha-subunit in the tympanic wall of rat cochlear duct. J. Histochem. Cytochem. 38:225-232, 1990.

Jewell EA, Lingrel JB. Comparison of the substrate dependence properties of the rat $\mathrm{Na}, \mathrm{K}-\mathrm{ATP}$ ase alpha 1 , alpha 2, and alpha 3 isoforms expressed in HeLa cells. J. Biol. Chem. 266:1692516930, 1991.

KerR TP, Ross MD, ERnst SA. Cellular localization of Na+, K+-ATPase in the mammalian cochlear duct: significance for cochlear fluid balance. Am. J. Otolaryngol. 3:332-338, 1982.

Kim JH, Sizov I, Dobretsov M, von Gersdorff H. Presynaptic Ca2+ buffers control the strength of a fast post-tetanic hyperpolarization mediated by the alpha3 $\mathrm{Na}(+) / \mathrm{K}(+)$-ATPase. Nat. Neurosci. 10:196-205, 2007.

Konishi T, Mendelsohn M. Effect of ouabain on cochlear potentials and endolymph composition in guinea pigs. Acta Otolaryngol. 69:192-199, 1970.

Kuijpers W, Bonting SL. The cochlear potentials. I. The effect of ouabain on the cochlear potentials of the guinea pig. Pflugers Arch. 320:348-358, 1970.

Kusakari J, Ise I, Comegys TH, Thalmann I, Thalmann R. Effect of ethacrynic acid, furosemide, and ouabain upon the endolymphatic potential and upon high energy phosphates of the stria vascularis. Laryngoscope 88:12-37, 1978.

Lang H, Schulte BA, Schmiedt RA. Ouabain induces apoptotic cell death in type I spiral ganglion neurons, but not type II neurons. J. Assoc. Res. Otolaryngol. 6:63-74, 2005.

McGrail KM, Phillips JM, Sweadner KJ. Immunofluorescent localization of three Na,K-ATPase isozymes in the rat central nervous system: both neurons and glia can express more than one Na,KATPase. J. Neurosci. 11:381-391, 1991.

McGuirt JP, Schulte BA. Distribution of immunoreactive alpha-and beta-subunit isoforms of Na,K-ATPase in the gerbil inner ear. J. Histochem. Cytochem. 42:843-853, 1994.

Moseley Ae, Williams MT, Schaefer TL, Bohanan CS, Neumann JC, Behbehani MM, Vorhees CV, Lingrel JB. Deficiency in Na,KATPase alpha isoform genes alters spatial learning, motor activity, and anxiety in mice. J. Neurosci. 27:616-626, 2007.

Munzer JS, Daly SE, Jewell-Motz EA, Lingrel JB, Blostein R. Tissueand isoform-specific kinetic behavior of the Na,K-ATPase. J. Biol. Chem. 269:16668-16676, 1994.

Nakazawa K, Spicer SS, Schulte BA. Ultrastructural localization of Na,K-ATPase in the gerbil cochlea. J. Histochem. Cytochem. 43:981-991, 1995.

Nesher M, Shpolansky U, Rosen H, Lichtstein D. The digitalis-like steroid hormones: new mechanisms of action and biological significance. Life Sci. 80:2093-2107, 2007.

O'Brien WJ, Lingrel JB, Wallick ET. Ouabain binding kinetics of the rat alpha two and alpha three isoforms of the sodium-potassium adenosine triphosphate. Arch. Biochem. Biophys. 310:32-39, 1994.

Peters TA, KujJpers W, Curfs JH. Occurrence of NaK-ATPase isoforms during rat inner ear development and functional implications. Eur Arch Otorhinolaryngol 258:67-73, 2001.

Pressley TA. Phylogenetic conservation of isoform-specific regions

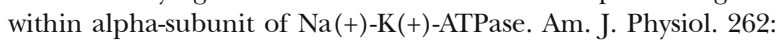
C743-C751, 1992.
Pyott SJ, Glowatzki E, Trimmer JS, Aldrich RW. Extrasynaptic localization of inactivating calcium-activated potassium channels in mouse inner hair cells. J. Neurosci. 24:9469-9474, 2004.

Pyott SJ, Meredith AL, Fodor AA, Vazquez AE, Yamoah EN, Aldrich RW. Cochlear function in mice lacking the BK channel alpha, beta1, or beta4 subunits. J. Biol. Chem. 282:3312-3324, 2007.

Rasband MN, Peles E, Trimmer JS, Levinson SR, Lux SE, Shrager P. Dependence of nodal sodium channel clustering on paranodal axoglial contact in the developing CNS. J. Neurosci. 19:75167528, 1999

RyAN AF, WATTS AG. Expression of mRNAs encoding alpha and beta subunit isoforms of the Na,K-ATPase in the rat cochlea. Mol. Cell. Neurosci. 2:179-187, 1991.

Schmiedt RA, Okamura HO, Lang H, Schulte BA. Ouabain application to the round window of the gerbil cochlea: a model of auditory neuropathy and apoptosis. J. Assoc. Res. Otolaryngol. 3:223-233, 2002.

SCHONER W, Scheiner-Bobis G. Endogenous and exogenous cardiac glycosides and their mechanisms of action. Am. J. Cardiovasc. Drugs 7:173-189, 2007.

Schulte BA, Adams JC. Distribution of immunoreactive Na+, K+ATPase in gerbil cochlea. J. Histochem. Cytochem. 37:127-134, 1989.

Schulte BA, Steel KP. Expression of alpha and beta subunit isoforms of Na,K-ATPase in the mouse inner ear and changes with mutations at the Wv or Sld loci. Hear. Res. 78:65-76, 1994.

Senatorov VV, Mooney D, Hu B. The electrogenic effects of Na(+)-K (+)-ATPase in rat auditory thalamus. J. Physiol. 502(Pt 2):375$385,1997$.

SpoenduIN H. Innervation of the cochlear receptor. In: Moller A (ed) Basic mechanisms in hearing. New York, Academic, pp. 185-230, 1973.

ten Cate WJ, Curtis LM, Rarey KE. Na,K-ATPase alpha and beta subunit isoform distribution in the rat cochlear and vestibular tissues. Hear. Res. 75:151-160, 1994.

vON KRIEgstein K, Schmitz F. The expression pattern and assembly profile of synaptic membrane proteins in ribbon synapses of the developing mouse retina. Cell Tissue Res. 311:159-173, 2003.

WANG LE, CAO KL, YIN SK, WANG Z, CHEN ZN. Cochlear function after selective spiral ganglion cells degeneration induced by ouabain. Chin. Med. J. (Engl) 119:974-979, 2006.

WANGEMANN P. Supporting sensory transduction: cochlear fluid homeostasis and the endocochlear potential. J. Physiol. 576:1121, 2006.

Weber PC, Cunningham CD, 3Rd, Schulte BA. Potassium recycling pathways in the human cochlea. Laryngoscope 111:1156-1165, 2001.

Zahler R, Zhang ZT, Manor M, Boron WF. Sodium kinetics of Na,KATPase alpha isoforms in intact transfected HeLa cells. J. Gen. Physiol. 110:201-213, 1997.

Zheng JL, GAO WQ. Analysis of rat vestibular hair cell development and regeneration using calretinin as an early marker. J. Neurosci. 17:8270-8282, 1997.

Zuo J, Curtis LM, Yao X, Ten Cate WJ, Rarey KE. Expression of Na, K-ATPase alpha and beta isoforms in the neonatal rat cochlea. Acta Otolaryngol. 115:497-503, 1995. 